\title{
INFLUENCE OF CRYSTALLOGRAPHIC ORIENTATION ON CREEP BEHAVIOR OF ALUMINIZED NI-BASE SINGLE CRYSTAL SUPERALLOYS
}

\author{
F. H. Latief ${ }^{1}$, K. Kakehi ${ }^{1}$, H. Murakami ${ }^{2}$, K. Kasai ${ }^{2}$ \\ ${ }^{1}$ Department of Mechanical Engineering, TokyoMetropolitanUniversity, Tokyo, Japan \\ ${ }^{2}$ Hybrid Materials Center, High Temperature Materials Unit, National Institute for Materials Science (NIMS), Tsukuba, Japan
}

Keywords: Ni-based superalloy, single crystal, creep behavior, aluminide coating, microstructure, crystallographic orientation

\begin{abstract}
The effect of chemical compositions and secondary crystallographic orientation dependence on the formation of diffusion layer and creep behavior were investigated. Three alloys of different generations: PWA $1480\left(1^{\text {st }}\right.$ generation $)$, CMSX-4 $\left(2^{\text {nd }}\right.$ generation) and TMS-75 ( $3^{\text {rd }}$ generation), were studied. After aluminized coating process, creep rupture test were performed at $900{ }^{\circ} \mathrm{C}$ and $392 \mathrm{MPa}$. The creep rupture properties of the alloys with and without the aluminized coating treatment were compared. The coating treatment resulted in a significant decrease in rupture lives for three alloys. No reductions in rupture elongation were observed. Creep strength was significantly degraded with aluminide coating due to the diffusion layers formed under coating layer. Creep fractures of the coated materials were essentially controlled by the crack nuclei in the coated layer. It was also found that the specimens with (100) side-surface showed longer creep rupture life than the specimens with (110) sidesurface, which means the results were anisotropic with respect to the secondary orientation which is normal to the primary orientation. The anisotropic creep behavior was caused by the different arrangement of $\{111\}<101>$ slip systems between the two side-surface specimens. The results obtained in this study suggest the importance of secondary orientation normal to the component surface on designing the single-crystalline turbine blades.
\end{abstract}

\section{Introduction}

The superior mechanical properties of Ni-based superalloys have been established for industrial gas turbines and jet engines applications. In order to increase the efficiency of power generating gas turbines, higher turbine inlet and turbine blade operating temperatures are required [1]. Gas turbine blade superalloys should possess a good resistance to surface degradation by oxidation and hot corrosion. Therefore, the surface protection of the blades by coatings is applied to turbine blades to improve environmental resistance. Aluminide coatings prepared by pack cementation process [2] are used to generate good protection against high temperature oxidation and hot corrosion in high temperature applications. Aluminide coatings have been popularly used in Ni-based superalloys for high temperature applications [3]. For improving the oxidation resistance of superalloys, aluminum is diffused into their surfaces to convert them to an intermetallic compound, beneath which a reactiondiffusion zone usually forms. The life limits of turbine blades can be influenced by the properties of the coating-substrate region.

Although Ni-based superalloys have an outstanding mechanical strength to very high temperatures, they tend to be vulnerable to environment attack due to the addition of refractory alloying elements that provide their high temperature strength. However, interdiffusion of elements between the superalloy substrate and the coating layer takes place when aluminized superalloys are thermally exposed at high temperature conditions, resulting in a change in the microstructure of the substrates [4]. Interdiffusion zone between the coating layer and superalloy substrate has become a serious problem because of formation of secondary reaction zone (SRZ) [4,5] and topologically close-packed (TCP) phases [6]. However, the damage mechanisms by aluminide coatings are not well understood. Localized damage in the blades may not only be caused by the irregular stress and temperature distribution applied to the blade, but also affected by the secondary orientation which is normal to the primary orientation. The main objective of this study is to investigate the damage mechanism of aluminized Ni-based single crystal superalloys during creep and influential factors, such as secondary crystallographic orientation and chemical composition.

\section{Experimental Procedures}

Three different generations Ni-base single crystal superalloys, PWA 1480 ( $1^{\text {st }}$ generation), CMSX-4 ( $2^{\text {nd }}$ generation) and TMS75 ( $3^{\text {rd }}$ generation), were used as substrate materials in the present study. The chemical composition and heat treatment of Ni-based superalloys are presented in Tables I and II, respectively. The crystallographic orientation of superalloys was analyzed by the Xray Laue reflection method. The (100) and (110) side-surfaces creep specimens (Figure 1) were prepared by electric discharge machining (EDM) with a cross-section area of $2.8 \mathrm{~mm} \times 2.8 \mathrm{~mm}$ and the gauge length of $19.6 \mathrm{~mm}$. The stress orientation of all the specimens was within 4 degrees of $\langle 001\rangle$. The specimens were mechanically polished down to 1200 mesh by emery paper and ultrasonically cleaned in acetone bath for $10 \mathrm{~min}$ prior to aluminizing process. The polished specimens were then embedded in a $\mathrm{Al}_{2} \mathrm{O}_{3}$ retort containing a mixture of 24.5 mass \% Al, 24.5 mass \% $\mathrm{Fe}, 49$ mass $\% \mathrm{Al}_{2} \mathrm{O}_{3}$ and 2 mass $\% \mathrm{NH}_{4} \mathrm{Cl}$ powders and heated at $1000^{\circ} \mathrm{C}$ for $5 \mathrm{~h}$ in flowing argon for aluminizing treatment, called as pack cementation process. The creep rupture tests were performed at $900{ }^{\circ} \mathrm{C}$ and $392 \mathrm{MPa}$ with a parallel load direction to $<001>$ direction. The changes in microstructure, after coating treatment and creep rupture test, were observed by scanning electron microscopy (SEM) and transmission electron microscopy (TEM). The texture and preferred crystallographic orientation were identified using electron backscatter diffraction (EBSD). 
Table I. Chemical Composition of Alloys (in Mass\%)

\begin{tabular}{lcccccccccc}
\hline & $\mathrm{Co}$ & $\mathrm{Cr}$ & $\mathrm{Mo}$ & $\mathrm{W}$ & $\mathrm{Al}$ & $\mathrm{Ti}$ & $\mathrm{Ta}$ & $\mathrm{Re}$ & $\mathrm{Hf}$ & $\mathrm{Ni}$ \\
\hline PWA 1480 & 5.2 & 10.0 & - & 4.0 & 5.0 & 1.4 & 12.1 & - & - & bal \\
CMSX-4 & 9.6 & 6.4 & 0.6 & 6.4 & 5.7 & 1.0 & 6.5 & 2.9 & 0.1 & bal \\
TMS-75 & 12 & 2.9 & 2.0 & 6.0 & 6.1 & - & 6.1 & 5.0 & 0.1 & bal \\
\hline
\end{tabular}

Table II. Heat Treatment Condition of Alloys

\begin{tabular}{crr}
\hline & Solution Heat Treatment & Aging Treatment \\
\hline PWA 1480 & $1282^{\circ} \mathrm{C} / 1 \mathrm{~h}+1287^{\circ} \mathrm{C} / 2 \mathrm{~h}+1294^{\circ} \mathrm{C} / 1 \mathrm{~h} \mathrm{GFC}$ & $1080^{\circ} \mathrm{C} / 4 \mathrm{~h} \mathrm{AC}+870^{\circ} \mathrm{C} / 32 \mathrm{~h} \mathrm{AC}$ \\
CMSX-4 & $1277^{\circ} \mathrm{C} / 2 \mathrm{~h}+1288^{\circ} \mathrm{C} / 2 \mathrm{~h}+1296^{\circ} \mathrm{C} / 3 \mathrm{~h}+1304^{\circ} \mathrm{C} / 3 \mathrm{~h}+1313^{\circ} \mathrm{C} / 2 \mathrm{~h}+$ & $1140^{\circ} \mathrm{C} / 4 \mathrm{~h} \mathrm{GFC}+870^{\circ} \mathrm{C} / 20 \mathrm{~h} \mathrm{GFC}$ \\
& $1316^{\circ} \mathrm{C} / 2 \mathrm{~h}+1318^{\circ} \mathrm{C} / 2 \mathrm{~h}+1321^{\circ} \mathrm{C} / 2 \mathrm{~h} \mathrm{GFC}$ & \\
TMS-75 & $1240^{\circ} \mathrm{C} / 1 \mathrm{~h}+1280^{\circ} \mathrm{C} / 2 \mathrm{~h}+1300^{\circ} \mathrm{C} / 2 \mathrm{~h}+1320^{\circ} \mathrm{C} / 8 \mathrm{~h} \mathrm{GFC}$ & $1150^{\circ} \mathrm{C} / 4 \mathrm{~h} \mathrm{GFC}+870^{\circ} \mathrm{C} / 20 \mathrm{~h} \mathrm{GFC}$ \\
\hline *GFC = Gas Furnace Cooling; $\mathrm{AC}=$ Air Cooling
\end{tabular}

${ }^{*} \mathrm{GFC}=$ Gas Furnace Cooling; AC $=$ Air Cooling

(a)



(b)



Figure 1. Arrangement of $\{111\}<101>$ slip systems for two kinds of specimens: (a) (100) and (b) (110) side-surface creep specimens.

\section{Results}

\section{Microstructures After Coating Treatment}

The optical and SEM micrographs of the three superalloy substrates are shown in Figure 2. The microstructure of the coating-substrate region can be seen in the SEM micrograph of the coated and heat-treated sample shown in Figure 3. It revealed that the coating-surface region could be divided into three different zones: the outer protective additive layer, a diffusion zone and the parent substrate. The diffusion layer, termed as interdiffusion zone (IDZ), was formed between the coating layer and the substrate after coating treatment for both (100) and (110) side-surface specimens in all aluminized substrates with various thicknesses. The average thickness of IDZ was $12 \mu \mathrm{m}$ for (100) side-surface and $14 \mu \mathrm{m}$ for (110) side-surface in aluminized PWA 1480 superalloy as shown in Figures 3a and 3d. The average thickness of IDZ in aluminized CMSX-4 superalloy was $8 \mu \mathrm{m}$ for (100) side-surface and $10 \mu \mathrm{m}$ for (110) side-surface as shown in
Figures $3 \mathrm{~b}$ and 3e. As for aluminized TMS-75 superalloy, the average thickness of IDZ was similar to be about $5 \mu \mathrm{m}$ for both orientations as shown in Figures 3c and 3f. In fact, the difference in the IDZ thickness took place in all aluminized specimens. The coating treatment resulted in the alteration of effective crosssectional area.

\section{Creep Rupture Test}

The creep curves of three different superalloys with (100) and (110) side-surfaces under a stress of $392 \mathrm{MPa}$ at a temperature of $900{ }^{\circ} \mathrm{C}$ are shown in Figures 4. The creep rupture life and reduction in creep rupture life for (100) and (110) side-surfaces are presented in Table III. TMS-75 exhibited the longest creep life both in bare and coated specimens for (100) and (110) sidesurfaces among three alloys. The second longest was CMSX-4. This occurrence is due to the chemical composition of superalloys 
where CMSX-4 and TMS-75 contain 3 and 5 mass \% Re, respectively. Moreover, the creep rupture life was shorter in all coated specimens compared to the bare specimens both for (100) and (110) side-surfaces. Meanwhile, the coated specimens with (100) side-surface exhibited a longer creep life than the coated specimens with (110) side-surface. The difference in creep rupture life between (100) and (110) side-surface orientations exhibited that the crystallographic orientation affected the mechanical properties of the superalloys. Concisely, the anisotropic creep behavior was occurred and obviously demonstrated by the difference in creep rupture life at different side-surface orientations in coated Ni-base superalloys as represented in Figure 1.


Figure 2. Optical and SEM micrographs of three different superalloys: (a) PWA 1480, (b) CMSX-4, and (c) TMS 75.

(100)



PWA 1480

CMSX-4

TMS-75

Figure 3. Cross-section images of aluminized superalloys: (a,d) PWA 1480, (b,e) CMSX-4 and (c,f) TMS-75 with (a,b,c) for (100) subsurface and (d,e,f) for (110) side-surface specimens. 



Figure 4. Creep curves of Ni-based single crystal superalloys: (a) PWA 1480, (b) CMSX-4 and (c) TMS-75.

\section{Microstructures After Creep Rupture Test}

The reduction in effective cross-sectional area leads to the increment of the effective stress. Further information for the alteration of effective cross-sectional area and effective stress after creep rupture test are summarized in Table IV. The $\{110\}$ specimens demonstrated a higher alteration of effective crosssectional area and effective stress than those of $\{100\}$ specimens. However, the reason for the increment of the effective stress triggered by the extension of diffusion layer thickness obtained during plastic deformation which associated with the microstructural change. As represented in Figure 5, the substrate diffusion zone (SDZ) was formed in aluminized PWA 1480 superalloy whereas the secondary reaction zone (SRZ) was not present because of the recrystallization was not observed in this study. As shown in table IV, the average thickness of diffusion layer was $19 \mu \mathrm{m}$ for (100) side-surface and $21 \mu \mathrm{m}$ for (110) sidesurface. The TCP phase was not observed in PWA 1480. In aluminized CMSX-4 superalloy, the SDZ having needle-like TCP precipitates was formed for both side-surfaces orientations. As a consequence, the diffusion layer thickness increased to about 21 $\mu \mathrm{m}$ for (100) side-surface and $24 \mu \mathrm{m}$ for (110) side-surface due to the formation of SDZ after creep rupture test as seen in Figure 6.

Table III. Creep Life Ratio of (110) to (100) Specimens

\begin{tabular}{lccc}
\hline & \multicolumn{2}{c}{ Creep Life (h) } & Ratio of (110) to \\
& $(100)$ & $(100)$ & 0.88 \\
\hline PW 1480 & 76 & 67 & 0.93 \\
CMSX-4 & 260 & 242 & 0.81 \\
TMS-75 & 525 & 428 & \\
\hline
\end{tabular}

Table IV. Decrease Ratio in Effective Cross-Section Area (\%)

\begin{tabular}{ccccc}
\hline & \multicolumn{2}{c}{$\begin{array}{c}\text { Total Depth of IDZ } \\
\text { and SDZ }(\mu \mathrm{m})\end{array}$} & \multicolumn{2}{c}{$\begin{array}{c}\text { Decrease Ratio in } \\
\text { Effective } \\
\text { Cross-Section Area (\%) } \\
\end{array}$} \\
& $(100)$ & $(110)$ & $(100)$ & $(110)$ \\
\hline PW 1480 & 19 & 21 & 2.7 & 3.0 \\
CMSX-4 & 21 & 24 & 3.0 & 3.4 \\
TMS-75 & 30 & 37 & 4.3 & 5.2 \\
\hline
\end{tabular}


The aluminized TMS-75 superalloy had an identical microstructure as the aluminized CMSX-4 superalloy. Afterwards, the voids were obvious as well as locally distributed inside the SDZ for both specimens with (100) and (110) side-surfaces as presented in Figure 7. The diffusion layer thickness was altered to be about $30 \mu \mathrm{m}$ for (100) side-surface and $37 \mu \mathrm{m}$ for (110) sidesurface. Figures 8a-b and 9a-b are the corresponding orientation maps assigned as face-centered cubic (fcc) and body-centered cubic (bcc) structures, respectively. The image quality map (IQ) confirms the TCP phase and voids corresponding to Figures 8a-b and 9a-b are shown in Figures $8 c$ and 9c, respectively. In these figures, the last images are the single-crystal substrate and orientation maps are displayed from the reference direction (RD), which is normal to the substrate/coating interface. It is clear from these figures that the surface aluminized layer consists of bcc polycrystalline grains while the IDZ consists of bcc and fcc phases. Most importantly, the SRZ was not observed both in (100) and (110) side-surfaces.
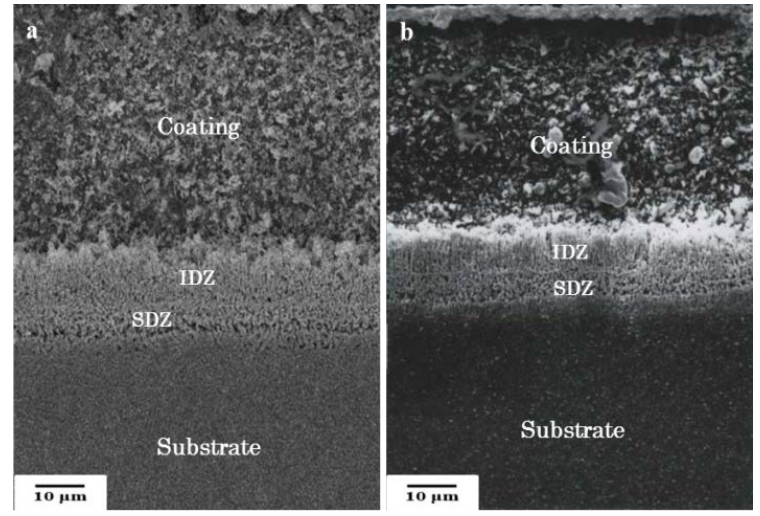

Figure 5. Cross-section images of creep ruptured PWA 1480: (a) (100) and (110) side-surface specimens.

\section{Fracture Surfaces}

The longest creep rupture life was reached by the TMS-75 superalloy. The creep lives between (100) and (110) side-surface orientations denoted the highest difference value that is $97 \mathrm{~h}$ in aluminized TMS-75 specimens compared to other specimens. Also, the difference of creep rupture life between the two sidesurface orientations was tangible for the other aluminized specimens but they were smaller than that of the TMS-75 superalloy. It proved that the anisotropic creep properties occurred in all aluminized specimens. Therefore, in order to clarify the anisotropic creep properties, the fracture surfaces were observed for both orientations as seen in Figure 10. The fracture surface consisted of dimples produced during creep deformation in both orientations as indicated by arrows as seen in Figure 10. Besides, the fracture surfaces exhibited two different fracture modes which can be classified as dimple fracture region (mode I) and slip region (mode II) where mode I and mode II regions were separated by the black line. The presence of the two different fracture modes on the fracture surface simultaneously suggests a mixed mode of failure during creep rupture tests at $900{ }^{\circ} \mathrm{C}$.

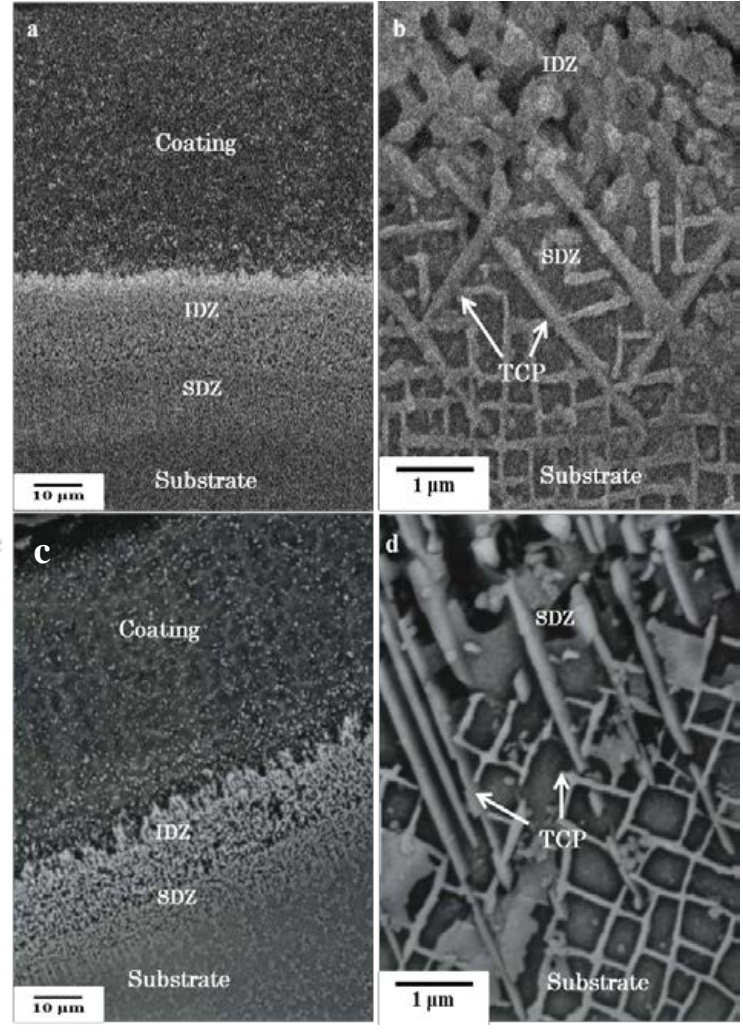

Figure 6. Cross-section images of creep ruptured CMSX-4: (a) (100) and (b) (110) side-surface specimens whereas (b) and (d) are magnified images of (a) and (c), respectively.

\section{Discussion}

\section{Effect of Chemical Composition}

CMSX-4 and TMS-75 had longer creep lives compared to PWA 1480 (Figure 4). Figure 11 shows dislocation structures of interrupted crept specimens at $900{ }^{\circ} \mathrm{C}$. The Burgers vector was determined as $\langle 110\rangle$ by the contrast visibility of the dislocation at $900{ }^{\circ} \mathrm{C}$. The dominant deformation mode in these three alloys is a combination of $\mathrm{a} / 2<110>$ dislocation bowing on the $\{111\}$ plane in the matrix and climbing along the $\gamma / \gamma^{\prime}$ interface (Figure11). The clear differences in deformation mechanism in the substrate were not observed among three alloys. One of the factors affects the difference in creep lives is the chemical composition of the superalloys. CMSX-4 and TMS-75 contain 3 and 5 mass \% of Re whereas PWA 1480 is free of Re. The addition of Re has some advantageous effects on single crystal superalloys. The large and slow diffusing element Re segregates mainly in the matrix $(\gamma)$ phase [7]. In addition to the solid solution strengthening effect of Re in the matrix, rhenium atoms tend to cluster $[8,9]$, thereby hindering dislocation movement. Finally, since Re segregates mainly in the matrix phase and has a large atomic radius, it influences the misfit between matrix and $\gamma^{\prime}$ lattice parameter $[10,11]$. Otherwise, it is also reported that adding Re to single crystal superalloys tends to form Re-rich topologically closed packed (TCP) phase precipitation which is known to reduce creep rupture strength [12]. The advantage the solid solution 
strengthening effect by Re addition would be more pronounced than disadvantage of Re-rich topologically closed packed (TCP) phase precipitation.



Figure 7. Cross-section images of creep ruptured TMS-75: (a) (100) and (b) (110) side-surface specimens whereas (b) and (d) are magnified images of (a) and (c), respectively.



Figure 8. Corresponding orientation maps (from Figure7a) assigned as (a) fcc and (b) bcc structures (c). Image quality map showing the TCP phase and voids in (100) side-surface specimen.

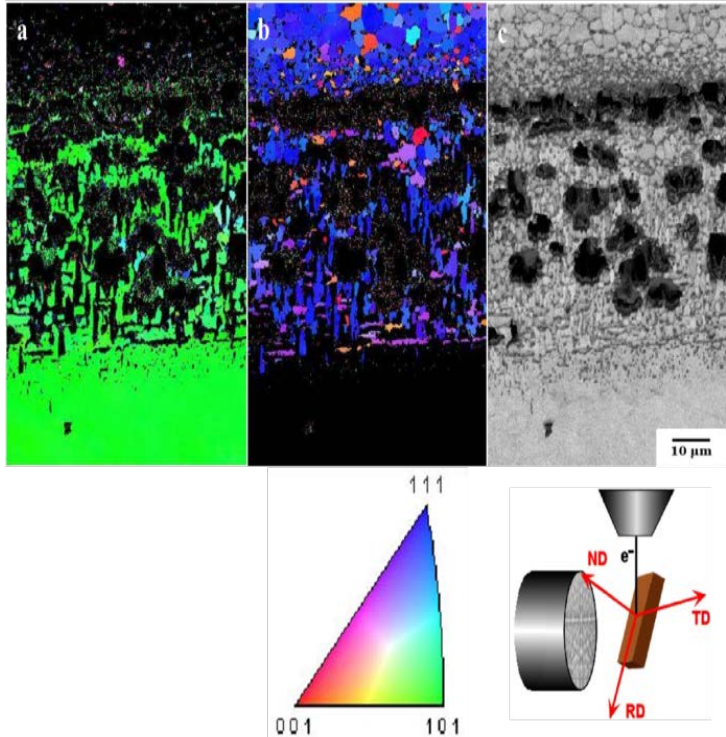

Figure 9. Corresponding orientation maps (from Figure 7c) assigned as (a) fcc and (b) bcc structures. (c) Image quality map showing the TCP phase and voids in (100) side-surface specimen.



Figure 10. Fracture surfaces of creep ruptured TMS-75: (a) (100) and (b) (110) side-surfaces specimens. 


\section{Effect of Coating Treatment}

The main objective of the protective coating is to serve as a suspension between the substrate and the environment to prevent degradation in an aggressive environment. Although the protective coating is not specially designed to enhance the mechanical properties of the material, its strain behavior and toughness are important with respect to its ability to protect the surface and to prevent crack initiation under mechanical loading [13]. As shown in Figure 4, the creep rupture life of aluminized specimens was shorter than that of the bare specimens. This suggested that creep fracture of the coated materials would be essentially controlled by the coated layers induced by the diffusion of aluminum from the protective coating into the base metal (substrate).
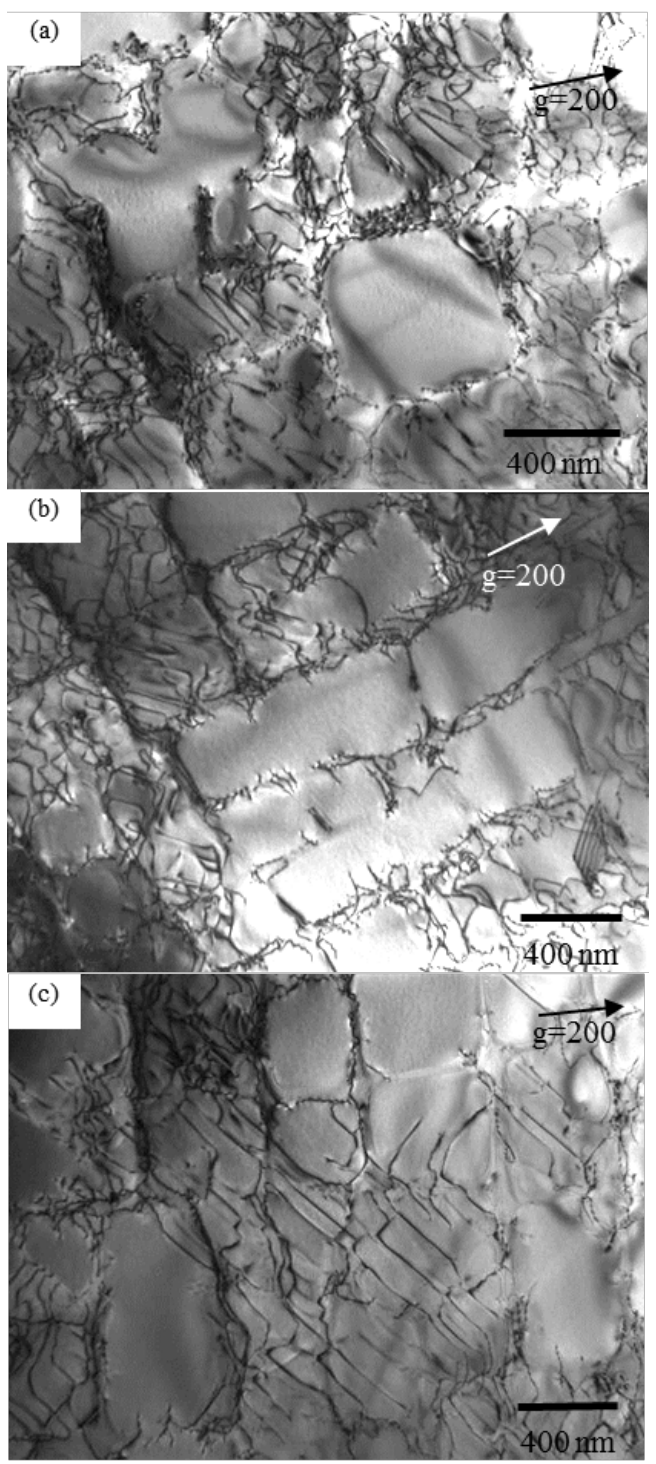

Figure 11. Dislocation structures of interrupted crept specimens at $900^{\circ} \mathrm{C}$. (a) PWA1480 ( $\left.\varepsilon=0.5 \%\right)$, (b) CMSX-4 ( $\left.\varepsilon=0.5 \%\right)$ and (c) TMS-75 ( $\varepsilon=0.4 \%)$. BD 001.
The decrease of the effective cross section area by formation of coating layers would be one of the factors to reduce creep strength. However, its effect issmall as shown in Table IV, therefore, it is not to enough to explain the reduction of creep life. The increment of the aluminum concentration in interdiffusion zone (IDZ) could lead to lowering in strength and premature failure of the specimen. Kang [13] showed the cracks nucleated at the free surface of the parent material whereas, for the coated condition, crack nucleation occurred in the coated layer rather than in the parent substrate for the conventionally and directionally solidified nickel-base alloys, Rene80. The main reason for the preferential formation of microcracks in the coated layer is attributed to the significantly higher hardness of the diffusion zone in the coated layer relative to the substrate [13]. In CMSX4, the micro-Vickers hardness of interdiffusion zone was more than twice as high as that of the substrate. The reduction in creep strength also might be due to weakening of atomic bonds, since the aluminum is a metal with low melting point so its effect could be considered as similar to that of other low melting metals [14].

When the aluminized specimens are applied to high temperature environments and stress [15], the interdiffusion of elements between the single crystal substrate and the coating layer takes place. However, the outward diffusion of Ni from the substrate leads to the enrichment of refractory elements and promotes the formation of topologically close-packed (TCP) phases. Re and W would promote the precipitation of TCP phase [15]. As the TCP phase is precipitated, the creep properties of superalloys are obviously diminished [16]. The TCP precipitates are found both in the aluminized CMSX-4 and TMS-75 superalloys since both superalloys have 3 and $5 \%$ Re content. On the other hand, the TCP phase could not be observed in the aluminized PWA 1480 superalloy due to likely free of Re containing as reported [17]. The precipitation of TCPs at high temperatures is mostly associated with the formation of voids which may potentially act as initiation sites for fracture [18]. The voids are apparent in aluminized TMS-75 as shown in Figure 7. It is commonly referred to as Kirkendall effect where the voids are formed due to the different diffusion rate of two or more metal atoms [19]. When the coated specimens are exposed at high temperature, the volume changes at the interface of coating and substrate by transformation of $\beta$-NiAl into $\gamma^{\prime}-\mathrm{Ni}_{3} \mathrm{Al}$ lead to the $\mathrm{Al}$ diffuses outward from the substrate diffusion zone (SDZ) as it oxidizes, forming the voids in the SDZ.

It can be realized from the results of this research that the microstructural and mechanical changes of the surface layer by aluminide coating treatment are very detrimental to the rupture properties of the single crystal superalloys.

\section{Effect of Secondary Crystallographic Orientation}

It has been reported that the mechanical properties of Ni-base single crystal superalloys are noticeably influenced by crystallographic orientation [20]. Therefore, aluminized coatings obtained by pack cementation on different crystallographic surfaces of Ni-base single crystal superalloy might bring about different structures. It is visible in the TMS-75 superalloy which the creep lives between (100) and (110) side-surfaces are more distinctive than the other superalloys as displayed in Table III. In brief, the anisotropic creep properties are the most pronounced in the aluminized TMS-75. 
(a)

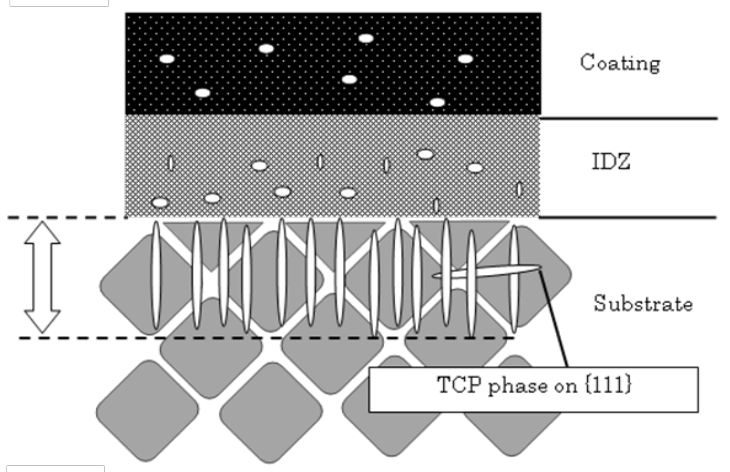

(b)



Figure 12. Schematic of TCP preferred precipitation orientation and voids formation for: (a) (100) and (b) (110) side-surfaces.

In order to explain this phenomenon, the relationship between the arrangement of slip systems and the mechanism of deformation fracture should be considered. The outward diffusion of $\mathrm{Ni}$ from the substrate leads to the enrichment of refractory elements and promotes the formation of topologically close-packed (TCP) phases that severely degrade the mechanical properties of aluminized specimen. The $\sigma$ phase, one of the TCP phases, forms coherently on $\{111\}$ planes in platinum-modified aluminized Nibased single-crystal substrates [6]. The schematic of TCP phase growth in both orientations is illustrated in Figure 12. The TCP phases grow up with a particularly intersected order by making an angle of $45^{\circ}$ to the substrate for (100) side-surface and having perpendicular as well as parallel to the substrate for (110) sidesurface. The TCP preferred precipitation orientation has affected the extension of zone under the IDZ, termed as SDZ, which occurred during plastic deformation. In this study, the SDZ is present instead of SRZ since the recrystallization could not be observed. In fact, the presence of SDZ results in the degradation of creep rupture life of the aluminized superalloys. This phenomenon is caused by the difference in SDZ thickness which is influenced by the geometry of TCP phase inside SDZ. The depth of TCP phase measured from Figures 8 and 9 for TMS-75 was $19 \mu \mathrm{m}$ for (100) side-surface and $24 \mu \mathrm{m}$ for (110) sidesurface. Therefore, the penetrated TCP phase plays an important role of high diffusion path for refractory elements to enhance further growth of diffusion layers in (110) side-surface.
The penetration of TCP phase into SDZ was very deep. The $\sigma$ phase formed as thin continuous film on the $\{111\}$ planes coherently [7]. The interface between TCP and the matrix at high temperatures is regularly associated with interfacial de-cohesion which may potentially act as initiation sites for crack [18]. The presence of TCP during service depletes the elements such as W, $\mathrm{Cr}$, Mo and Re, which enter into the TCP phase and reduce their solid strengthening in the matrix located adjacent to TCP phase. The depletion zone would provide the crack initiation site and its propagation path.

As shown in Figure 10, the fracture surfaces exhibited two different fracture modes. In the mode I region, small micro-voids form and coalesce in the interior of the substrate. Whereas in the mode II region, crack propagates along $\{111\}$ crystallographic planes which is the normal direction makes an angle of $54.7^{\circ}$ with the tensile stress axis. Thus, the operation of $\{111\}<101>$ slip system would result in the slip-band de-cohesion fracture along $\{111\}$ slip planes near the surface. The ratio or percentage of $\{111\}$ plane (compared to the overall area) was estimated from Figure 10. After measurement, the percentage of crystallographic $\{111\}$ facets associated with the activated slip system was about $12 \%$ for the specimen with (100) side-surface and $23 \%$ for the specimen with (110) side-surface. It follows that the specimens with (110) side-surface have a larger percentage of crystallographic $\{111\}$ facets than that of the specimens with (100) side-surface. The operation of $\{111\}<101>$ slip system would be more activated in (110) side-surface specimen than (110) side-surface specimen.

Table V. Resolved Shear Stress $(\tau)$ on Each of $\{111\}<101>$ Slip Systems for Two Kinds of Specimens.

\begin{tabular}{|c|c|c|c|}
\hline $\begin{array}{c}\text { Side-Surface } \\
\text { Orientation }\end{array}$ & Group* & $\begin{array}{c}\text { Principal } \\
\text { Slip System } \\
\end{array}$ & $\tau$ \\
\hline \multirow{8}{*}{100} & \multirow{4}{*}{$\mathrm{T}$} & 1. (111)[101] & \multirow{4}{*}{$\frac{1}{\sqrt{6}}\left(\sigma_{22}-\sigma_{33}\right)$} \\
\hline & & 2. (111)[110] & \\
\hline & & 3. (111)[101] & \\
\hline & & 4. $(111)[101]$ & \\
\hline & \multirow{4}{*}{ W } & 5. (111)[011] & \multirow{4}{*}{$\frac{1}{\sqrt{6}}\left(\sigma_{22}-\sigma_{11}\right)$} \\
\hline & & 6. (111)[011] & \\
\hline & & 7. (111)[011] & \\
\hline & & 8. (111)[011] & \\
\hline \multirow{8}{*}{110} & \multirow{4}{*}{$\mathrm{T}$} & 1. (111)[101] & \multirow{3}{*}{$\frac{1}{\sqrt{6}}\left(\sigma_{22}-\sigma_{33}\right)$} \\
\hline & & 2. (111)[011] & \\
\hline & & 3. (111)[101] & \\
\hline & & 4. (111)[011] & \\
\hline & \multirow{4}{*}{ W } & 5. (111)[011] & \multirow{4}{*}{$\frac{1}{\sqrt{6}}\left(\sigma_{22}-\sigma_{11}\right)$} \\
\hline & & 6. (111)[101] & \\
\hline & & 7. (111)[101] & \\
\hline & & 8. (111)[011] & \\
\hline
\end{tabular}

*If one of slip systems ( $\mathrm{T}$ group) operates preferentially, this results in a contraction of the thickness of specimen. If one of slip systems (W group) operate, this results in a contraction of the width. 
Each specimen has eight equivalent slip systems (Figure 1). The resolved shear stresses on the slip planes under a multi-axial stress state are shown in Table V. Under a multi-axial stress state, the resolved shear stress $\tau$ is decreased by the lateral stresses: $\sigma_{11}$ in the width direction or $\sigma_{33}$ in the thickness direction. Consequently, a smaller $\tau$ will be applied on the slip plane. However, a free surface of the specimen will be under the plane stress condition, that is, $\sigma_{11}$ and $\sigma_{33}$ is approximately equal to zero; therefore, a large shear stress $\tau$ will be applied on the slip plane near the surface. This large shear stress will promote the crack initiation and growth of cracks. Figure 13 shows relationship between crack length nucleated on the $\{111\}$ planes and the effective cross section area, assuming that a crack propagates on a (111) plane along the maximum shear stress direction. However, a crack propagation on $\{111\}$ planes causes more decrease in the effective cross section area of the (110) side-surface specimen than that of (100) side-surface specimen. In conclusion, the $\{110\}$ specimens exhibited lower creep rupture life than that of $\{100\}$ specimens, this is due to the difference in the crystallographic geometry of $\{111\}$ slip planes on which microcracks form in the IDZ hard layer and along the interface of TCP. However, despite the absence of TCP precipitation, PWA1480 showed the secondary orientation effect; therefore the hard layer in IDZ would be the common degradation mechanism for three alloys. TCP precipitation would be an additional degradation mechanism. Secondary orientation effect will be more pronounced in the actual turbine blade because the wall thickness of rotating blade is less than $1 \mathrm{~mm}$ in some locations.

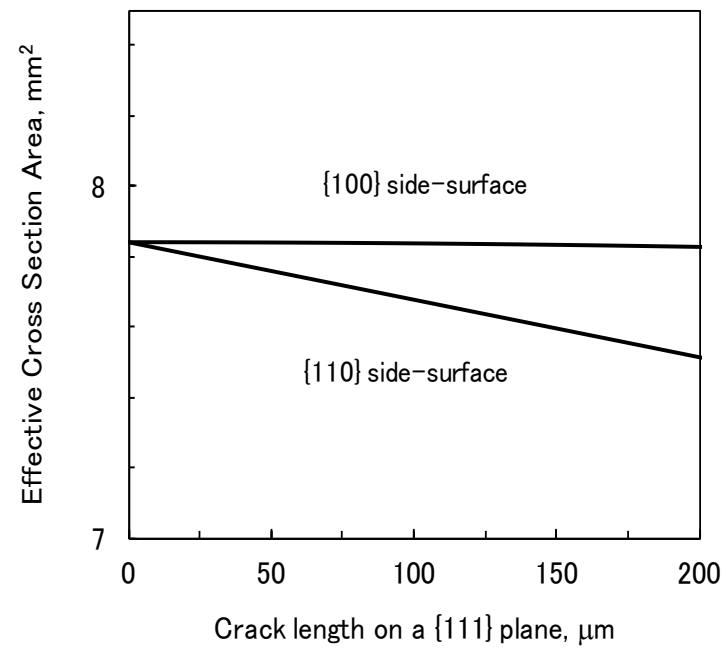

Figure 13. Relationship between the crack length on a (111) plane and the effective cross-section area.

\section{Conclusions}

The following conclusions can be withdrawn from this study:

Re addition improved creep strength of substrate; however, it developed TCP phase formation in the diffusion zone. The advantage by the solid solution strengthening effect by Re addition would be larger than disadvantage of Re-rich topologically closed packed (TCP) phase precipitation.

(ii) The creep strength was decreased by aluminized coating treatment. The surface micro crack caused by the higher-hardness layer in IDZ and TCP phase formation in SDZ decreased creep rupture life in aluminized specimens.

(iii) In three alloys, the aluminized specimens with (100) side-surface had longer creep rupture life than that with (110) side-surface, this is due to the difference arrangement in the crystallographic geometry of $\{111\}$ slip planes on which micro-cracks form. In TMS-75, the influence of secondary orientation on creep life was the most pronounced among three alloys because TCP precipitation developed profoundly.

\section{Acknowledgement}

The authors would like to gratefully acknowledge to Dr. Harada of NIMS (National Institute for Materials Science), Tsukuba, for the provision of materials.

\section{References}

[1] M. Biel, B. Dubiel and A. CzyrskaFilemonowicz,"Single Crystal Nickel-Base Superalloys for Gas Turbine Blades and Vanes,"Metallurgy and Foundry Engineering, 27 (2001) 209-227.

[2] D.K. Das, V. Singh, S.V. Joshi,“Evolution ofAluminide Coating Microstructure on Nickel-Base Cast Superalloy CM-247 in a Single-StepHigh-Activity Aluminizing Process," Metallurgical and Materials Transactions, 29A (1998) 2173-2188.

[3] B.M. Warnes, "Reactive Elements Modified Chemical Vapor Deposition Low ActivityPlatinum Aluminide Coatings," Surface and Coatings Technology, 146-147 (2001) 7-12.

[4] H. Murakami and T. Sakai, "Anisotropy of Secondary Reaction Zone Formation in Aluminized Ni-Based Single-Crystal Superalloys,” ScriptaMaterialia, 59 (2008) 428-431.

[5] S. Walston, A. Cetel, R. MacKay, K. O’Hara, D. Duhl and R. Dreshfield, "Joint Development of a Fourth Generation Single Crystal Superalloys,” Superalloys 2004, Green K A et. al., eds, (TMS, Warrendale, PA, 2004), 15-24.

[6] C.M.F. Rae, M.S. Hook, R.C. Reed, "The Effect of TCP Morphology on the Developmentof AluminideCoated Superalloys,” Materials Science and Engineering A, 396 (2005) 231-239.

[7] R. Darolia, D.F. Lahrmann, R.D. Fields, R. Sisson, "Formation of Topologically Closed Packed in Nickel Base Single Crystal Superalloys," Superalloys 1988, S. Reichman, D.N. Duhl,G. Maurer, S. Antolovich and C. Lund, eds, (The Metallurgical Society,Warrendale, PA, 1988), 255-264.

[8] D. Blavette, A. Bostel, "Phase Composition and Long Range Order in $\gamma^{\prime}$ Phase of a Nickel Base Single Crystal Superalloy CMSX2: An Atom Probe Study,”ActaMetallurgica, 32 (1984) 811-816.

[9] N. Wanderka, U. Glatzel, "Chemical Composition Measurements of a Nickel-Base Superalloy by Atom 
Probe Field Ion Microscopy,"Materials Science and Engineering A, 203 (1995) 69-74.

[10] R. Voelkl, U. Glatzel, M. Feller-Kniepmeier, ActaMaterialia, 46 (1998) 4395-4404.

[11] C. Schulze, M. Feller-Kniepmeier, “Transmisson Electron Microscopy of Phase Composition and Lattice Misfit in the Re-Containing Nickel-Base Superalloy CMSX-10,” Materials Science and. Engineering A, 281 (2000) 204-212.

[12] T. Hino, T. Kobayashi, Y. Koizumi, H. Harada, T. Yamagata, Superalloys (2000) 729-735.

[13] S.B. Kang and Y. G. Kim, "The Influence of a Coating Treatment and Directional Solidification on the Creep Rupture Properties of a Nickel-Base Superalloy," Materials Science and Engineering, 83 (1986) 75-86.

[14] V.I. Nikitin and T.N. Grigor'eva,"Effect of Aluminizing on The Creep Strength of a Nickel Alloy in Some Environments,” Materials Science, 10 (1975) 5-9.

[15] R.M. Kearsey, J.C. Beddoes, K.M. Jaansalu, et al., "The Effects of Re, $\mathrm{W}$ and $\mathrm{Ru}$ on Microsegregation Behaviour in Single Crystal Superalloy,"Superalloys 2004, T.M. Pollock, H. Harada, R.C. Reed and. S. Walston, eds, (Proceedings of the Tenth International Symposium on Superalloys. Seven Springs, Metals and Materials Society, United States, 2004)801-810.

[16] K. Zhao, Y.H. Ma, L.H. Lou and Z.Q. Hu, “ $\mu$ Phase in a Nickel Base Directionally Solidified Alloy,” Materials Transactions, 46 (1) (2005) 54-58.

[17] B.C. Wilson and G.E. Fuchs, "The Effect of Secondary Gamma-Prime on the Primary Creep Behavior of Single-Crystal Nickel-Base Superalloys,” Metalurgical and Materials Transactions A, 41A (2010) 1235-1245.

[18] C.M.F. Rae, M.S.A. Karunaratne, C.J. Small, R.W. Broomfield, C.N. Jones and R.C. Reed, “Topologically Close Packed Phase in an Experimental RheniumContaining Single Crystal Superalloy,” T.M. Pollock, R.D. Kissinger, R.R. Bowman, et al., eds, (Proceeding of $9^{\text {th }}$ International Symposium on Superalloys, TMS, Warrendale, PA, USA, 2000) 767-776.

[19] A.D. Smigelskas and E.O. Kirkendall, "Zinc Diffusion in Alpha Brass,” Trans. AIME, 171 (1947) 130-142.

[20] H. Fujikawa, H. Makiura and S.B. Newcomb, "Microstructural Control of Oxidation and Corrosion Resistant Chromised Nickel Plated Layers for Fe-Ni-Cr Alloys,” Materials Science and Technology, 18 (2002) 1347-135 